\title{
Computer Based Tests for the Courses of Informatics and Statistics of the Health Care Specialties
}

\author{
Oskars Rasnacs ${ }^{1}$ MSc. math.; Maris Vitins ${ }^{2}$ Dr. sc. comp. \\ The University of Economics and Culture ${ }^{1}$; Faculty of Computing, University of Latvia ${ }^{2}$, Latvia \\ oskars.rasnacs@inbox.lv¹; maris.vitins@lu.lv²
}

\begin{abstract}
For informatics and statistics courses of the higher schools have a significant impact on the health care taking specialist's career. The first significant point of career is the defense of the diploma thesis. The aim of the study is to find out what affects the total assessment score of the computer-based tests. There are observed 151 health care student group from Latvian higher schools. The linear regression was used. The total score of the computer-based tests of informatics and statistics are not dependent from kind of test. By increasing the number of generated data sets during the study process, group average assessments of higher school informatics and statistics courses become better and closer to the optimum. According to authors' researches optimal average assessment is 7.6. By using the mathematical model, it is possible to predict precisely the group assessment of higher school informatics and statistics courses. These results are statistically significant.
\end{abstract}

Keywords: computer-based tests, informatics, statistics, university education.

\section{Introduction}

The objective of the higher education establishments is to prepare highly qualified specialists, including specialists of health care. One of the criteria of being well prepared health care specialist is knowledge and skills of informatics and statistics. In the world, many study aids have been worked out, and students have lots of opportunities to learn various aspects of informatics and statistics.

Information technology has made information superficially much easier to access and use. N. Vronska's research presents a more effective way of thinking about how to improve student learning in both traditional and distance learning environments. She emphasises the information competencies as a group of skills to identify an information need, as well as retrieving, evaluating, using and reconstructing the knowledge contents of the retrieved information resources (Vronska, 2014).

Health care students can master computer science and statistics:

- at lectures and practical classes;

- at consultations;

- studying appropriate literature;

- studying the classification schemas of data processing situations;

- reading scientific publications associated with specialty.

The authors see and offer more opportunities how to facilitate the learning process and improve the students' knowledge and skills of computer science and statistics. We should bear in mind that informatics and statistics courses of the higher schools have a significant impact on the care taking specialist's career, and first of all on the defense of the diploma thesis.

The problem: Assessments of the health care students' knowledge and skills of informatics and statistics courses at higher schools are high (median (Me) is 8) (Rasnacs, Vitins, 2018). However, there is a chance to optimize the students' assessments.

The aim of the study is to find out what affects the total assessment score of the computing tests.

\section{Methodology}

At modern higher schools, computer-based tests are widely used to check and assess the students' knowledge of various study courses. Final assessments of courses sometimes are marked as the total score of the computing tests.

Today, there is a wide variety of options of using tests. Multiple choice tests are only ones of the ways to test. With the help of tests, even essays, which are assessed manually, can be summarized. Research 
work with obtaining data and their processing are quite typical with informatics and statistics courses at higher schools. In order to check the results of the student's work, the lecturer can use computer-based tests to compare with the correct answer.

The authors were interested in the question: what factors affect the total assessment score of computerbased tests? Especially those factors which can be affected by the authors. Every lecturer, during the course of time, develops his/her study course and also the computerized tests if they are used at all. One of the factors, according to the authors, worth to be studied is the time factor. The second important factor is generated data sets associated with specialty, whether they are used and their volume during the study process. One more investigation fact should be taken into account that the data sets are given to the group of students not to individual students.

Hypothesis of the research: The more generated data sets associated with the specialty are used during the teaching process, the higher are the students' assessments of computing tests. That means, better knowledge and skills of informatics and statistics, and better prepared the new specialist.

Research objectives:

1. Work out an information system of computer-based knowledge tests with the orientation of higher education informatics and statistics courses.

2. During the course of time, to investigate the total assessments score of the higher education informatics and statistics courses depending on the used number of the generated data sets associated with specialty.

There are observed 151 health care student group from Latvian higher schools. The linear regression was used.

\section{Results and Discussion}

A computer-based test system was worked out and approbated for the higher school informatics and statistics courses to assess the knowledge and skills (Rasnacs, Vitins, 2012). The system is intended for tasks that need MS Excel files, and several correct answers are possible. Alongside with the authors developed system, Moodle (Moodle, 2019) and other testing systems popular in the world were used.

Input data of the information system of the lecturer's profile:

- the number of questions from which to make one random choice for the answer;

- tests tasks;

- multiple choice options;

- number of scores for multiple choice options;

- MS Excel files.

Input data of the information system of the student's profile - the chosen answers of the student. Output data of the student's profile - answers of the test tasks, their analysis within the test setting or recommendations within the setting of studies. Whereas in the output data of the lecturer's profile, all the input data and their analysis by all the students are seen.

During the course of time, the assessments of computer-based tests have not changed of the students' individual data $(\mathrm{M}=7.4$, linear regression, $\mathrm{t}$-test $\mathrm{p}=0.820)$. Even assessments of the students' groups data (151 groups) also have not changed during the course of time (linear regression, $t$-test $p=0.265$ ).

Courses of informatics and statistics are special, and their effect on the future of the new specialist has a far-reaching consequence. Assessments of these courses affect significantly the diploma thesis defense results and career in the labor market (Rasnacs, Vitins, 2018).

In order to develop additional recommendations for the use of computer-based tests of informatics and statistics courses, the authors participated in writing the scientific articles of health care.

To elaborate computer-based tests, it is important to generate a great number of tasks. Sometimes in the publications of health care are given means and standard deviation. But students must be able to work with data that are not normally distributed.

The authors generalized the models (Rasnacs, Vitins, 2012), demanding that the statistical parameters were similar as much as possible to those presented in the scientific publications. The aim of the data 
generation is to obtain the individual data values and answers of tasks - statistical parameters. At the beginning, the authors asked for one parameter - median, and to get the coefficient of determination to the target parameters as close as possible (Rasnacs, Vitins, 2012). During a period of time, the number of parameters increased - the authors additionally asked for quartiles, mean, standard deviation, $\mathrm{p}$ values of various statistical tests to reach the definite target values. Statistical parameters can be very diverse. They can be medians, modes, interquartile ranges, $p$ value of different statistical tests.

During the study process, students can be given generated data sets associated with specialty according to the statistical parameters mentioned in the scientific publications. The data sets can contain a different number of data processing situations depending on the course content and the given tasks (Rasnacs, Vitins, 2012). The authors have generated data about:

- $\quad$ psoriasis (Hartmane et al., 2018);

- influence of noise in ambulance vehicles on emergency service (Janssen, Dundurs, 2018);

- elective colonoscopy (Mickevica, Margaliks, Mamaja, 2018);

- fat mass index and fat-free mass index (Kalnina et al., 2018);

- $\quad$ septic patients (Bridina, Gintere, Krumina, 2017);

- neurosurgical spine operations (Murniece et al., 2017);

- leukaemia (Paule, Nikulsins, Gravele, 2017);

- childhood intussusception (Soldatenkova et al., 2017);

- undergoing hand surgery (Margaliks et al., 2017).

To prove the set hypothesis, the authors developed a following mathematical model by surveying 2213 health care students of 151 groups within 10 years from 2008 to 2017 (Figure 1). For three health care student groups, predictions were made concerning the average grade per group (in total 37 students) of high school informatics and statistics courses in 2018/2019 study year.

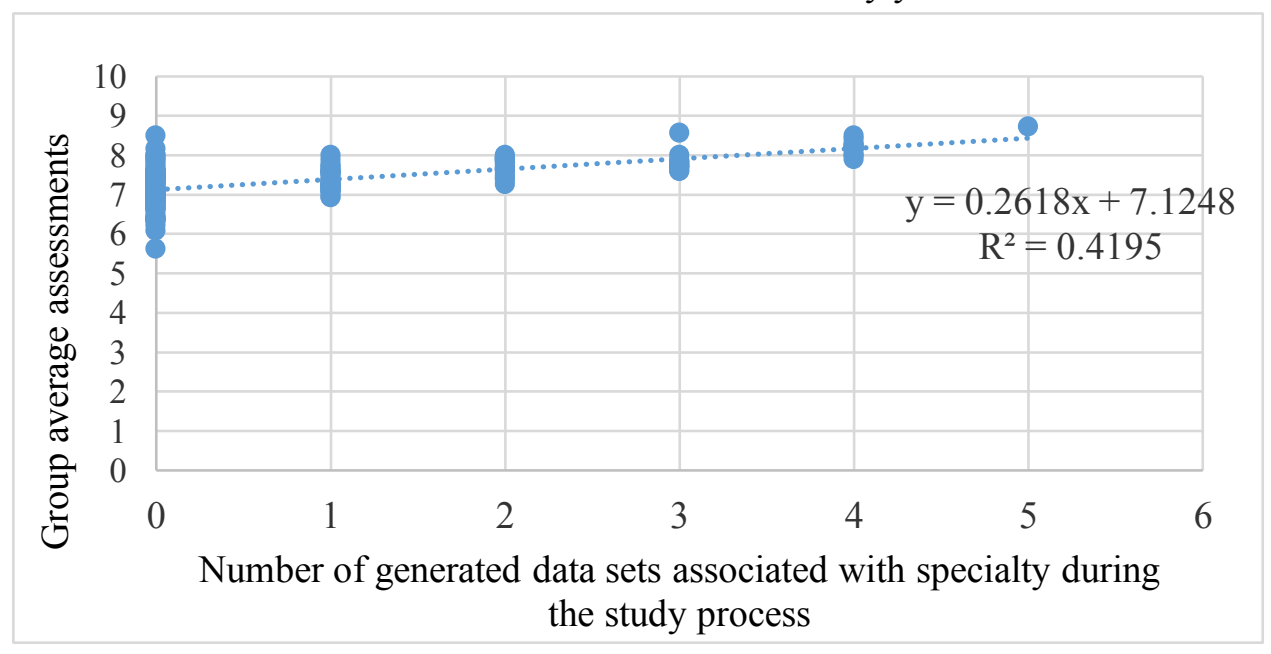

Figure 1. Linear regression of the group average assessments of higher school informatics and statistics courses depending on the number of generated data sets during the study process.

$\mathrm{x}$ - number of generated data sets associated with specialty during the study process, $\mathrm{y}$ - group average assessments of higher school informatics and statistics courses. The result shows that $y$ is dependent on $\mathrm{x}$ (linear regression, $\mathrm{t}$-test $\mathrm{p}<0.001$ ).

The model was approbated for three student groups. Two student groups were given five data sets associated with specialty. In accordance with the model, the group average assessment was $0.2618 \cdot 5+7.1248=8.4$. The average grades of those student groups were 8.5 and 8.6 , the relative error was $1 \%$ and $2 \%$, respectively. The third student group was given three data sets. In accordance with the model, the group average assessment was $0.2618 \cdot 3+7.1248=7.9$. The average grade of that student group was 8.5 and the relative error was $7 \%$. Different parameters and assessment models can be used for students' knowledge and skills assessment with computer-based tests which are included in the test maker programs (Fuentes et al., 2014; Fagbola, Adigun, Oke, 2013). For example, the number of true answers, the number of false answers, test execution time etc. When assessing, the authors recommend to use the students' achievements and historical experience of the corresponding assessments and linear approximation. 
The authors have surveyed the students' assessments of Latvian higher school informatics and statistics courses up to 2017 (Rasnacs, Vitins, 2018). The students' average assessment of informatics and statistics courses was 7.6. The authors also considered it important that the assessments of successful students were within the range from 5 to 10 scores. So, they accepted that the average assessment 7.6 is the optimal. The group average value was calculated for the differences of absolute value of the optimal assessment. For example, if the group average assessment is 7.8 , then $|7.8-7.6|=0.2$. Whereas, if the group average assessment is 7.3 , then $|7.3-7.6|=0.3$.

The authors were interested in the question - whether the mentioned absolute values are dependent on the number of generated data sets during the study process. By increasing the number of generated data sets during the study process, absolute values of deviations of the group average assessment decreases from the optimal 7.6 (linear regression, $\mathrm{t}$-test $\mathrm{p}=0.046$ ) (Figure 2). Coefficient of determination $\mathrm{R}^{2}$ is close to 0 , therefore prognoses cannot be made according to the equation (Figure 2).

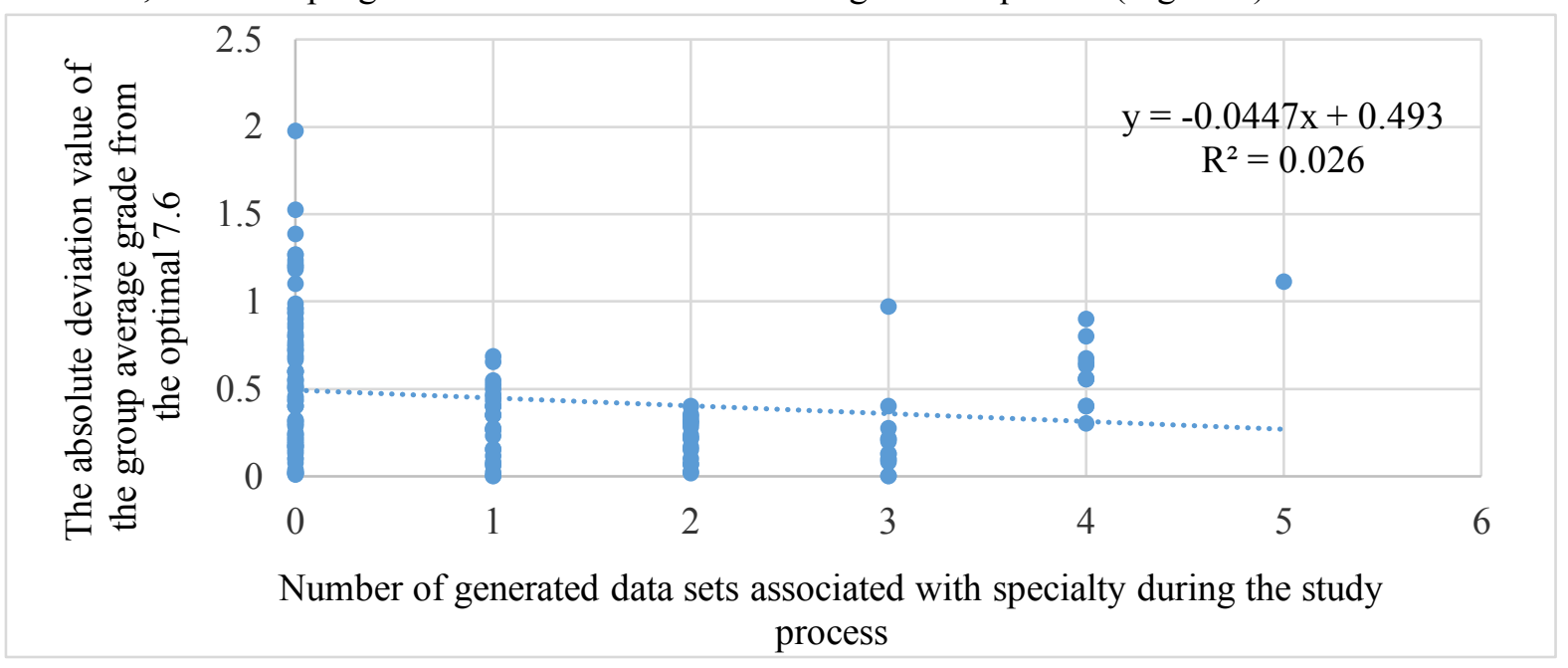

Figure 2. Linear regression of the absolute deviation value of the group average grade from the optimal 7.6 depending on the number of generated data sets during the study process.

\section{Conclusions}

Different computer-based tests are given to the students involved in the research. The students' results of the computer-based tests do not depend on the test structure, and they do not change during the course of time. The authors' hypothesis is proved. The more generated data sets associated with specialty are used during the study process and test, the higher are assessments of higher school informatics and statistics courses.

By using the mathematical model, it is possible to predict precisely the group assessment of higher school informatics and statistics courses.

By increasing the number of generated data sets during the study process, group average assessments of higher school informatics and statistics courses become closer to the optimum.

The authors recommend:

- to give generated data files for tests;

- to use the mathematical model for the data generation which immediately generates the data values corresponding to those given in the scientific publications.

In the test tasks the following steps are recommended:

- to substitute the missing symbols for the data, select queries and program codes (Ram Kedem, 2019);

- to calculate several statistics parameters which the student considers as correct;

- to give an analysis of the statements about the interpretation of the results;

- to use the students' historical experience of achievements for the assessment of test tasks. 


\section{Acknowledgements}

The research was developed under the University of Latvia contract "Innovative information technologies".

\section{Bibliography}

1. Bridina L., Gintere S., Krumina A. (2017). Laboratory Parameters and Treatment Applied to Septic Patients. In J. Zeimanis (Ed.), Collection of Scientific Papers: Research articles in medicine and pharmacy, 2016. Riga: Riga Stradins University, 5-10. Retrieved from https://www.rsu.lv/sites/default/files/book_download/rsu_research_articles_med_pharm_2016.pdf

2. Fagbola T.M., Adigun A.A., Oke A.O. (2013). Computer-Based Test (CBT) System for University Academic Enterprise Examination. International Journal of Scientific and Technology Research, 2 (8), 336-342. Retrieved from

https://www.researchgate.net/publication/263809997_Computer-

Based_Test_CBT_System_For_University_Academic_Enterprise_Examination

3. Fuentes J.M., Garcia A.I., Ramirez-Gomez A., Ayuga F. (2014). Computer-based tools for the assessment of learning processes in higher education: a comparative analysis. Proceedings of INTED2014 Conference, 8. Valencia, 976-984. Retrieved from https://www.researchgate.net/publication/271211156_computer-

based_tools_for_the_assessment_of_learning processes_in_higher_education_a_comparative_analysis

4. Hartmane I., Mikazans I., Ivdra I., Derveniece A. (2018). Evaluation of Clinical Efficacy and Safety in Treatment of Patients with Moderate and Severe Forms of Psoriasis with Combined Low Dose Methotrexate and Narrow Band UVB Therapy. In J. Zeimanis (Ed.), Collection of Scientific Papers: Research articles in medicine and pharmacy, 2017. Riga: Riga Stradins University, 5 - 10. Retrieved from

https://www.rsu.lv/sites/default/files/book_download/rsu_research_articles_med_pharm_2017.pdf

5. Janssen I.J., Dundurs J. (2018). Influence of Noise in Ambulance Vehicles on Emergency Service Personnel in North Germany and Latvia. In J. Zeimanis (Ed.), Collection of Scientific Papers: Research articles in medicine and pharmacy, 2017. Riga: Riga Stradins University, 11 - 15. Retrieved from

https://www.rsu.lv/sites/default/files/book_download/rsu_research_articles_med_pharm_2017.pdf

6. Kalnina L., Selga G., Sauka M., Larins V. (2018). Assessment of Fat Mass Index and Fat-Free Mass Index in Young Athletes. In J. Zeimanis (Ed.), Collection of Scientific Papers: Research articles in medicine and pharmacy, 2017. Riga: Riga Stradins University, 28-35. Retrieved from https://www.rsu.lv/sites/default/files/book_download/rsu_research_articles_med_pharm_2017.pdf

7. Margaliks M., Mickevica E., Jaunmuktane A., Stepanovs J., Mamaja B. (2017). EEG Controlled Sedation in Patients Undergoing Hand Surgery under Regional Anaesthesia: Dexmedetomidine vs. Propofol Target Controlled Infusion. In J. Zeimanis (Ed.), Collection of Scientific Papers: Research articles in medicine and pharmacy, 2016. Riga: Riga Stradins University, 20 - 29. Retrieved from

https://www.rsu.lv/sites/default/files/book_download/rsu_research_articles_med_pharm_2016.pdf

8. Mickevica E., Margaliks M., Mamaja B. (2018). Safety and Efficacy of Narcotrend Controlled Sedation with Dexmedetomidine vs. Propofol during Elective Colonoscopy. In J. Zeimanis (Ed.), Collection of Scientific Papers: Research articles in medicine and pharmacy, 2017. Riga: Riga Stradins University, 16 - 27. Retrieved from

https://www.rsu.lv/sites/default/files/book_download/rsu_research_articles_med_pharm_2017.pdf

9. Moodle. (2019). Create your perfect online learning environment. Retrieved from https://moodle.com/

10. Murniece S., Stepanovs J., Vjugins J., Vanags I., Mamaja B. (2017). Changes of Regional Cerebral Oxygen Saturation Using Near Infrared Spectroscopy during Neurosurgical Spine Operations in Prone Position. In J. Zeimanis (Ed.), Collection of Scientific Papers: Research articles in medicine and pharmacy, 2016. Riga: Riga Stradins University, 30 - 34. Retrieved from https://www.rsu.lv/sites/default/files/book_download/rsu_research_articles_med_pharm_2016.pdf

11. Paule S., Nikulsins S., Gravele D. (2017). Dynamics of Bone Marrow Cellularity in Paediatric Bcell Acute Lymphoblastic Leukaemia Measured by Automated Haematology Testing. In J. Zeimanis (Ed.), Collection of Scientific Papers: Research articles in medicine and pharmacy, 
2016. Riga: Riga Stradins University, 35 - 39. Retrieved from

https://www.rsu.lv/sites/default/files/book_download/rsu_research_articles_med_pharm_2016.pdf

12. Ram Kedem. (2019). SQL Tutorial with Exercises - Oracle. Retrieved from http://ramkedem.com/en/oracle/

13. Rasnacs O., Vitins M. (2012). An Information System to Learn Characteristic Sets of Words and to Examine Knowledge in Statistics. Databases and Information Systems VII. IOS Press, 361 - 370.

14. Rasnacs O., Vitins M. (2018). Opportunities to Improve the Digital Skills of Health Care Specialists. In V. Dislere (Ed.), The Proceedings of the International Scientific Conference Rural. Environment. Education. Personality (REEP), 11. Jelgava: LLU TF, 88 - 93. Retrieved from http://llufb.1lu.lv/conference/REEP/2018/Latvia_REEP_2018_proceedings_ISSN2255808X.pdf

15. Soldatenkova K., Laizans P., Zviedre A., Petersons A. (2017). Childhood Intussusception: 10year Experience at Children's Clinical University Hospital in Riga. In J. Zeimanis (Ed.), Collection of Scientific Papers: Research articles in medicine and pharmacy, 2016. Riga: Riga Stradins University, 11 - 19. Retrieved from

https://www.rsu.lv/sites/default/files/book_download/rsu_research_articles_med_pharm_2016.pdf

16. Vronska N. (2014). Students' information skills in the Latvia University of Agriculture. In V. Dislere (Ed.), The Proceedings of the International Scientific Conference Rural. Environment. Education. Personality (REEP), 7. Jelgava: LLU TF, 249-254. Retrieved from http://lufb.llu.lv/conference/REEP/2014/Latvia-Univ-Agricult-REEP-2014proceedings.pdf 